\title{
Transición y solidaridad internacional. La creación del Secretariado Internacional de Juristas para la Amnistía y la Democracia en Paraguay (SIJADEP)
}

\author{
Transition and international solidarity. The creation of the \\ International Secretari-at of Jurists for Amnesty and Democracy in \\ Paraguay (SIJADEP)
}

\author{
Magdalena Schelotto Altez \\ Université Lille III (Francia) \\ magda.schelotto@gmail.com
}

\begin{abstract}
Resumen
Mientras algunos países del Cono Sur retomaban su andadura democrática, la dictadura de Stroessner en Paraguay permanecía en el olvido de la comunidad internacional. Este artículo aborda la lógica y los mecanismos que funcionaron durante los acontecimientos fundadores y la transición del SIJAU (Secretariado Internacional de Juristas para la Amnistía en el Uruguay), creado para Uruguay, a la SIJADEP (Secretariado Internacional de Juristas para la Amnistía y la Democracia en el Paraguay. Este artículo se propone hacer un análisis de dos coloquios que marcaron la entrada del caso paraguayo en la órbita de trabajo del SIJAU para comprobar cómo el discurso sostenido por los juristas franceses se insertó en un contexto internacional más amplio bajo el lengua-je de los derechos humanos con el apoyo de otros organismos no gubernamentales y de la militancia exiliada.
\end{abstract}

Palabras clave

Paraguay; amnistía; redes transnacionales; derechos humanos

\begin{abstract}
When several countries in the Southern Cone regained their democratic path, the Stroessner dictatorship in Paraguay had still been forgotten by the international commu-nity. This article addresses the logic and mechanisms that worked during the founding events and the transition from SIJAU (International Secretariat of Jurists for Amnesty in Uruguay), created for Uruguay, to SIJADEP (International Secretariat of Jurists for Am-nesty and Democracy in Paraguay. This article intends to analyze two colloquia that marked the entry of the Paraguayan case into the SIJAU's work orbit to verify how the discourse held by French jurists was inserted in a broader international context under the language of human rights with the support of other non-governmental organizations and exiled militancy.
\end{abstract}

\section{Keywords}

Paraguay; amnesty; transnational networks; human rights

\section{Antecedentes y fundamentación teórica de la lucha del SIJADEP}

Esta obra está sujeta a la Licencia Reconocimiento-NoComercial-CompartirIgual 4.0 Internacional de Creative Commons. http://creativecommons.org/licenses/by-nc-sa/4.0/ 
Corría el año 1984 en Uruguay se llevan a cabo elecciones con miles de proscritos y el $1^{0}$ de marzo asumirá como presidente electo Julio María Sanguinetti tras la consulta de referéndum fallida realizada por los militares el 30 de noviembre de 1980 para perpetuarse en el poder ${ }^{1}$. La sorpresa fue aún mayor dado que pocos meses antes, el 30 de septiembre, los resultados obtenidos por Pinochet en Chile lo perpetuaba en el poder hasta el 11 de marzo de 1989 y la Junta Militar conservaba su papel en materia constituyente y legislativa. El resultado uruguayo fue saludado por la Conferencia Permanente de los Partidos Políticos de América Latina (CPPPAL) por la "voluntad de ese pueblo por retornar a un régimen de plena vigencia de las libertades democráticas. Por ello apoyamos la lucha de las fuerzas políticas que convergen en sus esfuerzos por restaurar la democracia en el país"2.

Por su parte, el SIJAU emitió un comunicado de prensa el mismo día de la votación felicitando lo que consideraba un doble triunfo: "El SIJAU saluda al pueblo uruguayo con motivo de este voto de coraje expresado después de siete años de feroz dictadura y en condiciones de extrema dificultad"3. También señalaba que constituía un evento mayor para toda América latina porque "es el rechazo de las democracias restringidas y manipuladas". Efectivamente, a pesar del caso chileno, un aire de retorno democrático corría por el Cono Sur latinoamericano con la asunción de Alfonsín en Argentina y las elecciones con civiles en Brasil.

El SIJAU (Secretariado Internacional de Juristas para la Amnistía en el Uruguay) nació en París en 1976. El principal promotor del SIJAU fue el magistrado Louis Joinet ${ }^{4}$. Entre otros, lo integraron Philippe Texier, Leandro Despouy, todos ellos especializados en la defensa de los DD.HH. y Jean-Louis Weil. Su actividad se prolongó de forma constante hasta marzo de 1985, fecha de la liberación de los últimos prisioneros políticos. Aprovechando la estructura del secretariado, continuaron sus actividades a favor de la liberación de los presos políticos de la dictadura de Alfredo Stroessner en Paraguay hasta su caída en 1989 bajo el nombre

\footnotetext{
${ }^{1}$ La Constitución Política plebiscitada por la dictadura cívico-militar uruguaya fue rechazada por el $57 \%$ de los votos, mientras que la consulta en Chile recibió el 67,04\% de los apoyos.

${ }^{2}$ Santo Domingo, mayo de 1981. Fuente: Fonds SIJAU Weil Uruguay, F delta rès 809 (7) (1-6)

${ }^{3}$ Original en francés, traducción de la autora. Fuente: Fonds SIJAU Weil Uruguay, F delta rès 809 (7) (1-6)

${ }^{4}$ Fallecido el 22 de diciembre de 2019, fue una referencia en el desarrollo y la promoción de los Derechos Humanos. Personaje incómodo en el ámbito judicial, egresado de la escuela de magistrados en 1966, en 1968 fundó el sindicato de la magistratura en Francia. Cuando Mitterrand llegó al poder en 1981 se convierte en asesor de varios ministros. Fue experto independiente y voluntario de la Comisión de Derechos Humanos de la ONU durante treinta y tres años, como tal recorrió el mundo escribiendo informes. Un hecho marcó para siempre su vínculo con el Uruguay. En 1976 le pidieron que hiciera un informe sobre el caso uruguayo para el Tribunal Russel donde se iba a realizar una sesión dedicada a Brasil y al Cono Sur. Por ese motivo consiguió el testimonio de Norma Scopise, militante tupamara, salvajemente torturada y que había presenciado el asesinato de su marido. Scopise se niega a testificar con la cara cubierta y pocos meses después saltará por un balcón de su casa cuando la vio rodeada por las Fuerzas Armadas. Su vínculo con la militancia uruguaya exiliada en Francia fue permanente hasta su fallecimiento, en particular con la asociación ¿Dónde Están? Francia, integrada en su mayoría por antiguos exiliados y que en 2017 cumplió veinte años de existencia.
} 


\section{Transición y solidaridad internacional. La creación del Secretariado Internacional de Juristas para la Amnistía y la Democracia en Paraguay (SIJADEP)}

de SIJADEP. Constituirse en una organización de juristas, aunque no era exclusivo, buscaba dejar fuera los problemas detectados en reuniones de solidaridad en las que intervenían directamente los partidos políticos y sus intereses particulares. Según Jean-Louis Weil: “Nos permitió evitar trampas a nivel político [...] No hubiésemos aguantado si hubiésemos trabajado con un solo partido o movimiento, era contrario a la idea de convencer a la opinión pública internacional"5.

Pero, ¿Cuáles fueron los vínculos del SIJAU ${ }^{6}$ con el final de la dictadura paraguaya? Este organismo había sido creado para romper el olvido por parte de la comunidad internacional frente a la dictadura uruguaya. En palabras de Jean-Louis Weil: ¿Por qué Uruguay? Principalmente por el "olvido" o "complot de silencio" de un país "pequeño", frente a la situación política que se vivía en Chile y Argentina, pero que poco a poco fue roto gracias a la labor de los exiliados ${ }^{7}$.

Desde su formación en 1976, el SIJAU estableció vínculos fluidos con otros organismos y en varios países, como veremos a continuación. En 1978, el SIJAU ya tenía secciones en Bélgica, Holanda, España, Suiza, Suecia, Estados Unidos, Italia, Austria, México, entre otros. El método del secretariado se basa en denuncias contra el régimen uruguayo por violaciones de la normativa jurídica ratificada por el país y algunas veces centrándose en casos particulares de presos políticos. Sus reclamos siempre irán apoyados por un gran respaldo en forma de firmas o de participación en los eventos de destacadas personalidades del ámbito jurídico internacional. Esto es un elemento clave, porque abrió el camino en la utilización del lenguaje y los métodos de las redes transnacionales de Derechos Humanos. Con ello, el SIJAU logró el apoyo de los distintos sectores de la diáspora uruguaya, evitando las diferencias partidarias y, por otro lado, logró tener eco en los organismos internacionales de Derechos Humanos, quienes tienen la capacidad de presionar a la dictadura.

Sus reclamos se extendieron a través de las redes de países por los que el SIJAU se expandía y la evolución de sus reclamos siguió los acontecimientos dentro del país, pero también los cambios políticos internacionales de la región y es este punto el que nos interesa para comprender en qué momento se comienza a trabajar por Paraguay.

\footnotetext{
${ }^{5}$ Entrevista realizada en noviembre de 2009 en París. Weil era abogado de Derecho Laboral pero animado por Joinet se integró en las labores del SIJAU convirtiéndose en su coordinador y miembro activo hasta su cierre en 1992.

${ }^{6}$ En este trabajo hacemos mención al SIJAU de forma que nos permita conocer el trabajo desarrollado desde 1985 para Paraguay con la creación del SIJADEP. El caso uruguayo ha sido documentado y analizado en la tesis doctoral de la autora: Schelotto Altez, Magdalena (2014). Aplicación de una metodología de análisis del discurso: la amnistía en el Uruguay post-dictatorial (tesis de doctorado inédita). Universidad Carlos III, Madrid, España.

${ }^{7}$ Es interesante ver la evolución discursiva de los exiliados que facilita su acercamiento a organismos como el SIJAU para que sus reclamos pudieran tener eco en organismos internacionales. Al respecto, para el caso uruguayo se puede consultar: Magdalena Schelotto, «La dictadura cívico-militar uruguaya (1973-1985): la construcción de la noción de víctima y la figura del exiliado en el Uruguay post-dictatorial », Nuevo Mundo Mundos Nuevos [En línea], Cuestiones del tiempo presente, Puesto en línea el 10 marzo 2015. URL: http://journals.openedition.org/nuevomundo/67888; DOI : https://doi.org/10.4000/nuevomundo.67888
} 
El SIJAU organizó cinco coloquios que sirvieron, entre otras cosas, para estructurar desde el punto de vista teórico y conceptual sus demandas. El primero, "Estado de excepción y derechos humanos en Uruguay". Celebrado en el Senado francés entre el 15 y 16 de diciembre de 1978 en París, recibió el apoyo del Movimiento Internacional de Juristas Católicos, la Asociación Internacional de Demócratas y la Federación Internacional de DD. HH. A continuación, en febrero de 1981 tuvo lugar en Ginebra el "Coloquio sobre la Política de institucionalización del estado de excepción y su rechazo por el pueblo uruguayo". Poco después, los días 17, 18 y 19 de junio de 1983 se celebró en San Pablo el "Coloquio sobre los fundamentos jurídicos de una verdadera apertura democrática en Uruguay". El cuarto coloquio, fue en Buenos Aires donde organizaron el "Coloquio sobre Uruguay y Paraguay. La Transición del Estado de excepción a la democracia", del 27 al 30 de septiembre de 19848. Estos dos últimos coloquios, en particular el lugar donde se celebran, muestran un acercamiento al Uruguay y a Paraguay que viene marcado por los cambios políticos que vive la región ya que se celebran en países, Brasil, en transición política si bien aún hay dictadura y Argentina donde ya gobernaba Alfonsín.

Además del contexto externo, cabe mencionar aunque sea de forma somera, algunos elementos internos del país guaraní que lo habían sometido en una grave crisis y facilitaron el decaimiento del régimen stronista sostenido por la matriz Estado, Partido Colorado y Fuerzas Armadas que fue perdiendo esa "franja de consensos" (Russo de Pagno, -). Pese a que nos encontremos frente a una transición "tradicional" (O'Donnell, 1988) o "vigilada" (Céspedes, 1988), ya que será un cambio político desde arriba, donde no hubo referéndum explícito ni ruptura pactada pero donde existía un claro consenso tácito de repudio. El comienzo de la década de los ochenta vino marcada por una fuerte crisis económica producto del descenso de los precios así como por el final de la faraónica construcción del proyecto binacional con Brasil de la represa de Itaipú. Los mayores socios de Paraguay, Argentina y Brasil, bajo medidas de austeridad impuestas por el Fondo Monetario Internacional no estaban en condiciones de asistirlo y el propio país guaraní vivió un crecimiento exponencial de la deuda externa en la década de los setenta. A esto se sumó la crisis interna en los apoyos de las Fuerzas Armadas al régimen así como la división interna del propio Partido Colorado (WOLA, 1988).

En el coloquio de París se sentaron las bases teóricas de la lucha del SIJAU en torno al concepto de amnistía que más tarde se plasmarían en el informe presentado en San Pablo:

"De defensiva debe convertirse en ofensiva. Así es el combate por la amnistía. Ofensiva igualmente esta lucha, si no la amnistía sobrevendrá un día concedida

\footnotetext{
${ }^{8}$ En nuestra investigación hemos podido localizar las actas publicadas correspondientes a los coloquios de París, Buenos Aires y Montevideo, los dos primeros en el Fondo SIJAU-Weil en la biblioteca La Contemporaine en la Universidad de Nanterre (Francia) y el último en la biblioteca de Amnistía Internacional Uruguay en Montevideo. El fondo SIJAU-Weil también contiene extensa documentación sobre la preparación de dichos eventos.
} 


\section{Transición y solidaridad internacional. La creación del Secretariado Internacional de Juristas para la Amnistía y la Democracia en Paraguay (SIJADEP)}

en un juego de fuerzas desfavorables [...] la amnistía es generalmente una decisión política que se traduce en una ley de "concesión" a los ciudadanos [...] Generalmente el poder cambia por vías más o menos violentas o democráticas. [...] no se trata ya de esperar que la amnistía sea concedida como consecuencia de un cambio de régimen. Ya es una lucha hacia un cambio de régimen, es pues una conquista y no algo regalado, una prima, a un cambio de régimen. Esto es fundamental. [...] amnistía general amplia y sin restricciones, pero en el estado, ninguna amnistía para los torturadores". (SIJAU,19859)

Según el "Informe Artucio", si bien se consideraba necesaria la defensa de los Derechos Humanos frente a la tortura, los crímenes, los secuestros o los decretos que violaban las leyes internacionales, entendían esta forma de proceder como un "combate defensivo". Este concepto de amnistía sostenido por el informe del SIJAU apuntaba ya a un modelo de transición. Por eso hablan de un "combate ofensivo", como algo por lo que se debe luchar (las condiciones en las que se debe dar, quienes se deben beneficiar, etc), como camino hacia una transición motivada por esa lucha y no como algo impuesto de forma pasiva. Sus pedidos de amnistía incluyen toda una serie de cambios, como la suspensión de los procesos penales, la anulación de las penas o la supresión de los antecedentes penales de las personas comprendidas por la amnistía y la imposibilidad de arrestar o investigar los crímenes en ella comprendidos. En definitiva, el SIJAU exigía una forma concreta de amnistía ligada al establecimiento de la transición democrática. En este sentido, parece interesante retomar el análisis de Lesgart ${ }^{10}$ (Lesgart, 2002) que plantea que en los años ochenta"la democracia política y la transición fueron utilizadas antes que nada como categorías que delimitaron el pasado y que construyeron un horizonte de expectativas". La amnistía defensiva plantea un horizonte donde la democracia es efectivamente un objetivo per se, oponiéndola al autoritarismo y cuya transición comprendía una serie de demandas concretas.

En esta articulación, el papel de los exiliados, principalmente en París, es clave como vínculo con el país de origen y porque son juristas locales, como el caso de Alejandro Artucio para el Uruguay, que bajo un conocimiento profundo del sistema jurídico en cuestión pueden proponer las bases de la amnistía que reclaman utilizando el lenguaje de los Derechos Humanos y bajo sus garantías.

\footnotetext{
${ }^{9}$ El informe presentado en el coloquio que tuvo lugar en San Pablo, Brasil, en 1983, aparece publicado en el libro resultado del coloquio que tuvo lugar al año siguiente en Buenos Aires (SIJAU,1985). El informe aparece en el Anexo IV.2, páginas 213-225. El informe fue hecho por Mercedes y Alejandro Artucio, ambos juristas uruguayos exiliados en Francia, miembros de la Comisión Internacional de Juristas y miembros activos del SIJAU, motivo por el cual se lo conoce como "Informe Artucio". ${ }^{10}$ Lesgart, Cecilia (2002). Usos de la transición a la democracia. Ensayo, ciencia y política en la década del ochenta. Estudios Sociales, Año XII, № 22-23, Santa Fé, Argentina, Universidad Nacional de Litoral, pp. 163-185.
} 


\title{
El Coloquio de Buenos Aires: Paraguay y el silencio de la comunidad internacional
}

\begin{abstract}
"Ya no se puede admitir que la sociedad internacional siga alegando desconocer lo que pasa en Paraguay. (...) Con razón Simone de Beauvoir decía "que lo más grave que tiene el escándalo es que uno se acostumbra". Contra esa concepción de las relaciones internacionales expresamos nuestra disconformidad". José Félix Fernández Estigarribia (SIJAU, 1985)
\end{abstract}

Con la ley de amnistía en Uruguay ${ }^{11}$ y la liberación de todos los presos, el SIJAU dio por cumplido su objetivo, pero el coloquio llevado a cabo en Buenos Aires en septiembre de 1984 y titulado "Coloquio sobre Uruguay y Paraguay. La Transición del Estado de excepción a la democracia”, hizo evidente la necesidad de trabajar por Paraguay ${ }^{12}$. Esta voluntad se fraguará con la conformación del SIJADEP, El Secretariado Internacional de Juristas para la Amnistía y la Democracia en Paraguay el año siguiente, en 1985. Utilizando la estructura y los lazos creados por el SIJAU, el SIJADEP trabajará atendiendo a las particularidades del caso paraguayo como veremos a continuación. Para ello, nos concentraremos en la evolución del discurso y de las demandas que conciernen al caso paraguayo entre el coloquio que tuvo lugar en Buenos Aires y el quinto coloquio, dedicado enteramente al Paraguay que fue realizado en Montevideo. De este modo, podremos comprobar el funcionamiento de las redes transnacionales no solo como mecanismo de denuncia, sino también como espacio de análisis y de creación teórica donde se presentan las pautas para una transición hacia la democracia.

Al comienzo del coloquio llevado a cabo en Buenos Aires, el jurista Jean-Louis Weil, coordinador del SIJAU, dijo en su presentación: "Si he escogido permanecer a un nivel de discurso institucional y normativo, es porque es así la misión del SIJAU" (SIJAU,1985). Esto marca, una vez más, el fuerte carácter jurídico y de defensa de la legalidad internacional al que se aferró el Secretariado en su defensa de la amnistía desde sus comienzos, formado en su mayoría por juristas. Una jornada entera fue dedicada a la situación paraguaya. Entre los oradores hubo personalidades como el escritor paraguayo Augusto Roa Bastos pero en su mayoría, eran juristas paraguayos y algunos miembros de partidos políticos como detallaremos a continuación. Luis A. Reck, abogado, profesor de la Universidad Católica de Asunción, dirigente internacional de la Democracia Cristiana. Alejandro Ladalardo,

\footnotetext{
${ }^{11}$ Ley 15.737 del 8 de marzo de 1985 que permitió la liberación de todos los presos políticos fue votada pocos días después de la llegada de Julio María Sanguinetti al gobierno. No obstante, distinguió entre presos comunes y aquellos detenidos por delito de homicidio, a los cuales la justicia civil le conmutó 3 días de pena por cada día de privación de libertad sufrida, quedando finalmente todos en libertad. Además, esta ley excluía de forma explícita los crímenes cometidos por funcionarios policiales o militares. La promulgación de la ley de Caducidad 15.848 del 22 de diciembre de 1986, dejará sin efecto este último punto. https://legislativo.parlamento.gub.uy/temporales/leytemp1350267.htm

12 En los documentos consultados en el Fondo SIJAU Weil, no hemos obtenido constancia de un debate previo interno sobre si volcarse o no en el trabajo por el caso paraguayo. No obstante, podemos deducir una total aceptación ya que prácticamente trabajan las mismas personas, a excepción de Juan Saavedra.
} 


\title{
Transición y solidaridad internacional. La creación del Secretariado Internacional de Juristas para la Amnistía y la Democracia en Paraguay (SIJADEP)
}

abogado, profesor, defensor del programa de presos políticos del Comité de Iglesias, Vicepresidente del Partido Demócrata Cristiano, miembro de A.A.L.A Paraguay. Euclides Acevedo, abogado, presidente del Partido Revolucionario Febrerista. Mario L. Mallorquín, abogado, ex ministro de Estado, Vicepresidente del Movimiento Popular Colorado. Justo Prieto, abogado, Profesor de Derecho Constitucional en la Universidad Católica de Asunción. Carlos Alberto González, abogado, decano de la Facultad de Derecho de la Universidad Católica de Asunción. José Félix Fernández Estigarribia, abogado, presidente de la Asociación de Abogados Latinoamericanos para los Derechos Humanos, A.A.L.A. Paraguay, profesor de derecho internacional en la Universidad Católica de Asunción. Domingo Laíno, economista, ex profesor de la Universidad Católica de Asunción, Vicepresidente del Partido Liberal Auténtico. Esther Prieto, abogada, ex funcionaria del Consejo Mundial de Iglesias.

Cada uno intervino en aspectos específicos de la situación paraguaya como la violación de los derechos constitucionales, la situación de los derechos políticos, el estado de sitio o la política internacional del Paraguay. Una de las ideas permanentes en las alocuciones, insistía en el hecho de que Paraguay estaba sumergido en el olvido por parte de la comunidad internacional y ese coloquio era un primer paso para modificar esa realidad. En palabras de Augusto Roa Bastos:

\begin{abstract}
"La invitación a participar en él a los representantes de la democracia paraguaya por parte del SIJAU constituye un reconocimiento y un honor. (...) una suerte de reparación moral en favor de la dura lucha de la democracia paraguaya contra la más vieja tiranía del continente, lucha como olvidada o marginada de la escena política internacional" (SIJAU, 1985).
\end{abstract}

En la misma línea, Justo Prieto cerraría su participación diciendo: "finalmente, todos celebramos la incorporación del Paraguay a la preocupación de todos los ciudadanos del mundo, quebrando así ese olvido" (SIJAU,1985) y parafraseando una expresión de la reforma de Córdoba ${ }^{13}$ insiste: "Las libertades que le faltan a Paraguay son las obligaciones que quedan a la comunidad internacional" (SIJAU,1985). Para el magistrado Salvatore Senese ${ }^{14}$, incluir el caso paraguayo por primera vez en un coloquio del SIJAU supone romper "un silencio demasiado largo" (SIJAU,1985).

Ese coloquio sienta las bases del SIJADEP, que formalizará su creación en 1985 con la celebración en Montevideo del quinto coloquio: "Paraguay: un desafío a la responsabilidad internacional". El SIJADEP tuvo un comité directivo compuesto por

\footnotetext{
13 Hace referencia a la Reforma Universitaria de Córdoba de 1918 que tuvo lugar en Argentina y que buscaba entre otras cosas la autonomía universitaria, en el Manifiesto de la Federación Universitaria de Córdoba del 21 de junio de 1918 decía: "Los dolores que nos quedan son las libertades que nos faltan".

${ }^{14}$ Salvatore Senese, magistrado italiano de la magnitud de Joinet en Francia, era miembro del Consejo superior de la Magistratura de Italia y de la Liga Internacional por los Derechos y la Libertad de los Pueblos, formó parte del comité director del SIJAU y del SIJADEP.
} 


\section{Magdalena Schelotto Altez}

personalidades de origen múltiple, muchos ya vinculados previamente al SIJAU. Su coordinador en Francia fue el militante chileno exiliado Juan Saavedra, contó con la participación activa de los abogados uruguayos Alejandro Artucio y Wilder Tayler, de Pila Salaberry, secretaria del SIJAU y del ya mencionado abogado paraguayo, Alejandro Ladalardo.

En Uruguay, el SIJADEP se instaló, como había sido el caso para el SIJAU, en la sede del Instituto de Estudios Legales y Sociales (IELSUR) donde trabajaba Tayler y al que también estaba vinculado Artucio. En la transición de uno a otro secretariado se decidió trabajar en la "continuidad" de métodos, con el mismo modelo pero teniendo en cuenta algunas peculiaridades del caso paraguayo. Había pocos presos políticos, por ello la amnistía no sería un elemento suficiente en sus reclamos. En el caso paraguayo, a esa altura del régimen, era el exilio la forma más fuerte de represión. Además se añadió en la prioridad y en el nombre del secretariado la lucha por la "democracia", aludiendo al aparente sistema democrático que guardaba el régimen y cuyo cuestionamiento estará muy presente en el siguiente coloquio ${ }^{15}$.

Frente a una autocracia longeva y monolítica, el Coloquio de Buenos Aires puso de relieve algunos aspectos que detallaremos en este apartado ya que nos permitirán comprender mejor el caso paraguayo y sus peculiaridades.Las intervenciones de los juristas paraguayos denuncian que desde 1954 bajo el stronismo, se vive una violencia institucionalizada que se apoya en las leyes "anticomunistas" 294/55 "de Defensa de la democracia" de los años 60 y 209/70 "De defensa de la paz pública y libertad de las personas" de septiembre de 1970 y en el permanente estado de sitio que deriva en persecuciones, torturas, detenciones, muertes, desapariciones y exilio, un millón de personas según Luis A. Resck, “el más numeroso, desgarrador y de más antigua data" (SIJAU, 1985). Esto supone treinta años gobernando bajo estado de sitio que según la propia constitución paraguaya debe de ser una medida de excepción en caso de conmoción interna o ataque exterior (art. 52 de la Constitución de 1940 y art. 79 de la Constitución de 1967). No obstante, la Constitución de 1940 sustrae la capacidad de declarar el estado de sitio al Parlamento para atribuírsela al presidente de la República. Posteriormente, la Constitución de 1967 ampliará las facultades del presidente, permitiéndole prohibir las reuniones y manifestaciones públicas durante el estado de sitio. Desde entonces, Stroessener prorroga mediante decreto cada noventa días la vigencia del estado de sitio. Esta situación es según Justo Prieto, usada como "técnica para amedrentar" (SIJAU,1985) provocando una fuerte autocensura. En palabras de Euclides Acevedo, el autoritarismo de Stroessner "es una forma de administración del estado que busca fundamentalmente la

\footnotetext{
${ }^{15}$ La información contenida en este párrafo fue obtenida gracias a la entrevista realizada a Wilder Tayler el 21 de noviembre de 2019. Abogado uruguayo, fue secretario general de la Comisión Internacional de Juristas (2007-2017), actualmente titular del Consejo Directivo de la Institución Nacional de Derechos Humanos y Defensoría del Pueblo en Uruguay. Wilder Tayler, que ya era un contacto dentro del país para el SIJAU desde antes de 1984, participó activamente en la preparación del coloquio en Buenos Aires y posteriormente en el de Montevideo. Después de este último, Leandro Despouy le propone integrar el SIJADEP y aceptó inmediatamente. Conocía el país porque allí vivió en los años setenta y luego hizo tres misiones en el país.
} 


\section{Transición y solidaridad internacional. La creación del Secretariado Internacional de Juristas para la Amnistía y la Democracia en Paraguay (SIJADEP)}

obediencia, la obsecuencia y la sumisión de una sociedad a través de los aparatos ideológicos y represivos del Estado" (SIJAU,1985). En otras palabras, bajo la figura del estado de sitio en Paraguay se detiene, se cierran medios de prensa, se destierra o se prohíbe casi todo. En este sentido, Justo Prieto dirá: "La perennidad del estado de sitio torna ilusorio el ejercicio de los derechos y lo transforma, no en un acto libre, sino en un acto de riesgo" (SIJAU,1985).

A la violación de las libertades y la autocensura provocadas por esta situación se sumaba la corrupción ya que, para ejercer cualquier puesto, hasta para ser maestro, había que afiliarse al partido colorado, haciendo del sistema educativo una herramienta que según Luis A. Reck "alienta el espíritu del servilismo" (SIJAU,1985). Sin olvidar que el sistema de aparente funcionamiento democrático, ya que se celebraban elecciones para las cuales el estado de sitio era levantado por veinticuatro horas y en las que el partido colorado obtenía siempre la mayoría absoluta del escrutinio.

Estos elementos denunciados en el Coloquio en cuanto a la violencia institucionalizada, al estado de sitio permanente, a la censura y las violaciones de libertades coinciden con el concepto de "estado omnívoro" (Ariditi, 1992) que hace referencia al hecho de que no se trata de un sistema hermético ya que no erradica completamente la disidencia pero que si tiene una voluntad "totalizante" que intenta evitar toda diferencia con el modo vertical, jerárquico y subordinado impuesto por el núcleo que toma las decisiones, a pesar de que mantiene una aparente legalidad formal en el funcionamiento de las instituciones.

Otro tema propio al caso paraguayo y planteado en el coloquio, es el problema de la tenencia de la tierra. En un país con un sesenta por ciento de población rural, Luis A. Resck denuncia la existencia de cinco mil familias sin tierra, a la que se añade la expulsión de campesinos de sus tierras incendiando sus casas y tras violentas persecuciones. En este sentido, la represión alcanza también a las Ligas Agrarias, que se organizan en cooperativas, que vivieron un período de grave persecución entre 1972 y 1974, consideradas como subversivas o comunistas. La Confederación Paraguaya de Trabajadores (CPT), único organismo reconocido por el gobierno, respondía a las directivas que el mismo poder ejecutivo establece ${ }^{16}$. Además del problema de la propiedad de la tierra, los miembros del SIJADEP denunciaban la mala distribución de la riqueza, mientras el 7\% de la población poseía el 75\% de los ingresos, un $42 \%$ solo ganaba el $7,7 \%$.

Por último, haremos referencia a dos aspectos que están relacionados y conciernen directamente el trabajo basado en el lenguaje transnacional de los derechos humanos encarnado por el SIJADEP para el caso paraguayo. Por un lado, la política

16 WOLA, 1988 Op.cit. El informe recogido por la Washington Office on Latin America recoge la situación agraria del país y el control férreo ejercido por el gobierno sobre la CPT frente al deseo de autonomía de los trabajadores rurales que representaban un alto porcentaje de la población. 


\section{Magdalena Schelotto Altez}

internacional del Paraguay y por otro, el estatus del país guaraní frente a la comunidad internacional.

Desde el punto de vista de la normativa internacional, el Pacto de San José de Costa Rica (Convención Interamericana de Derechos Humanos, CIDH) de 1969 no fue ratificado por el gobierno paraguayo como tampoco el Pacto Internacional de Derechos Civiles y Políticos de la ONU, evidenciando su falta de interés por ser medido por los estándares a los que compromete la ratificación de dichos acuerdos, basados en el respeto a los Derechos Humanos. Un aspecto en particular molesta al Estado paraguayo, ya que según el pacto de San José, se declaraba entre otros, la imposibilidad de restringir el derecho de expresión por vías o medios indirectos que buscasen impedir la comunicación y la circulación de ideas u opiniones (art. 13.3). El discurso de Belisario dos Santos Jr. denunciaba prácticas que iban en esa línea, tales como "el control de la producción y de la importación de papel, la imposición de cargas fiscales y la limitación del volumen de publicidad" (SIJAU,1985) que se suma a la represión directa de medios mediante censura, cierres parciales y clausuras.

Por su parte, los detalles facilitados por los que intervinieron sobre la presencia del caso paraguayo en el debate de la comunidad internacional en el Coloquio de Buenos Aires, pusieron en evidencia una situación olvidada, compleja y que, tras 30 años de dictadura, apenas empezaba a tener eco en los organismos de Derechos Humanos, como veremos a continuación. A este respecto, tomó la palabra en nombre del SIJAU el magistrado Luis Joinet, fundador del secretariado y miembro de la subcomisión de Prevención de las Discriminaciones y Protección de la Minorías de la ONU. Su intervención estuvo compartida con Esther Prieto, abogada paraguaya, mencionada anteriormente. Sus intervenciones pusieron de manifiesto que el caso paraguayo ya había sido tratado en altas instancias internacionales como la $\mathrm{CIDH}$, en varias oportunidades, o la OIT. No obstante, casi no había sido enunciado públicamente en las Naciones Unidas hasta 1983.

La CIDH llevaba varios años tratando casos individuales, esencialmente pidiendo al gobierno paraguayo que otorgara pasaportes a ciertas personalidades políticas, dada la situación general del país ${ }^{17}$. En referencia a este último punto, se elaboraron varios informes constatando la existencia de violaciones y haciendo propuestas "constructivas" (SIJAU,1985) en palabras de Joinet, tales como el levantamiento del estado de sitio y expresándose a favor de enviar una comisión de observadores al país. Si bien las autoridades no se opusieron, dieron respuestas dilatorias, que para Joinet suponían "un rechazo a cooperar".

En cuanto a la OIT, su comité de Libertades Sindicales constató violaciones en relación con los Convenios 87 y 98 sobre el ejercicio de las libertades sindicales y el derecho a la negociación colectiva que fueron elevadas al gobierno paraguayo. Así

17 Comisión Interamericana de Derechos Humanos. Organización de Estados Americanos OEA/Ser.L/V/II.43 Doc. 13 corr. 1, 31 enero 1978. Informe sobre la situación de los Derechos Humanos en Paraguay 


\section{Transición y solidaridad internacional. La creación del Secretariado Internacional de Juristas para la Amnistía y la Democracia en Paraguay (SIJADEP)}

mismo, la Comisión de expertos de la OIT emitió en $1981^{18}$ una resolución sobre el trabajo forzado al que se sometía a presos políticos condenados en aplicación de la Ley 209.

En lo que se refiere al tratamiento del caso paraguayo por parte de la ONU, el magistrado Joinet tuvo que hacer referencia a los diferentes procedimientos mediante los cuales se puede tratar la situación de un país en la ONU para ilustrar cómo el tratamiento de la situación paraguaya generó debate. Para ello distinguió, por un lado, el procedimiento confidencial, mediante el cual luego de haber pasado todos los filtros de selección y ser estudiado un caso, se emite una resolución solicitando al Estado que tome las medidas pertinentes. Por otro, existía el procedimiento público, que Joinet lamentaba que fuera tan poco utilizado, ya que, mediante el primer procedimiento, el debate era a puerta cerrada y las decisiones tomadas nunca se hacían públicas ${ }^{19}$. Pero el caso paraguayo vivió una situación peculiar ya que, siendo tratado de forma confidencial, apareció, aunque de forma indirecta, en un procedimiento público, como detallaremos a continuación y que fue desvelado por el propio Joinet en su intervención. El informe de Nicole Questiaux ${ }^{20}$, de la Comisión de Derechos Humanos de la ONU, consagrado a los estados de sitio y de excepción permanentes, evocaba en 1982 el caso paraguayo.

No será hasta 1983 cuando por primera vez se adopte una resolución pública sobre Paraguay. En ese año, la Federación Internacional para los Derechos Humanos, organismo consultivo de Naciones Unidas, encargó una misión de observación al abogado en París, François Cheron ${ }^{21}$. Su testimonio fue recogido en la sesión 36a de agosto de 1983 en el que establecía una relación directa entre la violación de los Derechos Humanos y la perpetuación del estado de excepción. Aprovechando su intervención, el representante costarricense pidió que fuera emitida una resolución, que según Joinet, contrariamente a lo esperado, recibió el apoyo de quince firmas, entre ellas la del experto norteamericano y fue adoptada por mayoría con dieciocho votos. La resolución instaba al gobierno paraguayo "a encarar el levantamiento del estado de sitio, para favorecer la promoción y el respeto de los derechos humanos en ese país". Pero en 1984, el tratamiento del caso paraguayo provocó un enorme debate en el que se mezclaron temas de fondo sobre la situación paraguaya y de procedimientos propios del funcionamiento de la asamblea. Mientras en la 42a

\footnotetext{
18 Los datos recogidos en el sitio oficial de la OIT permiten acceder a los Comentarios de las Comisiones de Expertos a partir de 1987.

19 Para comprender mejor los diferentes procedimientos ver: De Frouville, 0. (2006).Les organes subsidiaires de la Commission. En Emmanuel DECAUX (dir.), Les Nations Unies et les droits de l'homme - Enjeux et défis d'une réforme, Paris, Pedone, coll. « Fondation Marangopoulos pour les droits de l'homme ", $\mathrm{n}^{\circ}$ 9, 2006

20 Nicole Questiaux, Sous-Commission de la lutte contre les mesures discriminatoires et de la protection des minorités, Rapport sur les conséquences pour les Droits de l'homme des développements récents concernant les situations dites d'état de siège ou d'exception, 27 juillet 1982, UN Doc. E/CN.4/Sub.2/1982/15, p. 15.

${ }^{21}$ No se ha podido localizar el informe, François Cheron ya había realizado misiones de observación en Argentina y Uruguay en febrero de 1979.
} 


\section{Magdalena Schelotto Altez}

reunión del 32avo período de sesiones de la Comisión de Derechos Humanos se abordaba el caso paraguayo, Bulgaria pidió presentar enmiendas. Uruguay se opuso con el pretexto de que la Subcomisión ya había examinado el asunto. En las enmiendas propuestas por Bulgaria se solicitaba hablar de violaciones de Derechos Humanos cuando el proyecto de resolución, más moderado, solo solicitaba el levantamiento del estado de sitio. Endurecer el texto de la resolución causó un importante debate ya que Uruguay y Brasil se opusieron alegando que la situación paraguaya ya había sido tratada en el marco del procedimiento confidencial. Haciendo esto, ambos violaban la confidencialidad del procedimiento. Pero la comisión decidió postergar un año lo propuesto por estos dos últimos países. Tomando en cuenta este punto de desacuerdo sobre el procedimiento, la URSS propone que la resolución sobre Paraguay también fuera diferida a la sesión de 1985 así como la que concernía a Afganistán. En el fondo, el planteamiento de la URSS esperaba que, siguiendo esta lógica, el tratamiento de Afganistán también fuera postergado. En este sentido, algunas grandes potencias propusieron la inadmisibilidad de ambas resoluciones ya que ambos casos habían sido tratados en el marco del procedimiento confidencial. No obstante, Reino Unido se posicionó de forma contraria alegando que lo examinado en el procedimiento confidencial y la enmienda propuesta en el procedimiento público eran diferentes y por lo tanto, admisible. Su postura fue apoyada por Canadá. En ese punto del debate, el observador enviado por el gobierno paraguayo, ya que Paraguay no era miembro de la Comisión de Derechos Humanos, solo participaba bajo la figura de observador, declaró que la resolución tenía un carácter selectivo y discriminatorio. También argumentó que:

\footnotetext{
"La situación del Paraguay ya fue examinada en el marco del procedimiento confidencial con la total colaboración de la delegación paraguaya y en esa oportunidad se reconoció expresamente que el gobierno paraguayo estaba dispuesto a seguir cooperando con la Comisión, comunicándole nuevas observaciones, sobre la situación de los derechos humanos en el país, incluso un eventual proyecto de derogación del estado de sitio" (SIJAU, 1985)
}

El detalle de estos debates pone en evidencia las relaciones de poder ejercidas por algunos países en el momento de decidir el procedimiento para tratar la situación de un país. Además, según el relato del magistrado Joinet, permitieron que saliera a la luz la imbricada situación paraguaya y provocó al menos un compromiso del gobierno guaraní para cooperar, hasta se llegó a hablar incluso de una posible derogación del estado de sitio.

Irlanda también intentó que el debate fuese diferido, pero se decidió pasar a votar para intentar desbloquear la situación. La resolución fue finalmente adoptada bajo voto nominal a pedido de Nicaragua, con 36 votos a favor, 1 voto en contra (Uruguay) y 5 abstenciones (China, Chipre, Pakistán, Filipinas y Camerún). Brasil no participó en la votación y algunas de las delegaciones que votaron contra las 


\section{Transición y solidaridad internacional. La creación del Secretariado Internacional de Juristas para la Amnistía y la Democracia en Paraguay (SIJADEP)}

enmiendas de Bulgaria, fue el caso de Reino Unido, lo hicieron por temor a que fuese declarado inadmisible el proyecto por tratarse de la misma naturaleza que lo tratado bajo el procedimiento confidencial.

En agosto de 1984, se reunió la Subcomisión de derechos humanos y adoptó una nueva resolución por Paraguay. Fue adoptada por unanimidad, hecho sin precedentes. La resolución pide el levantamiento del estado de sitio y la promulgación de la amnistía como condición previa para una real apertura democrática.El debate y la primera resolución de 1983 generaron una toma de conciencia, en gran parte gracias al trabajo de denuncia hecho por organizaciones humanitarias y que repercutió en los organismos no gubernamentales consultivos de Naciones Unidas. ONGs tales como el Movimiento Internacional por la Unión Fraternal de las Razas y Pueblos que expresó la solidaridad africana con el pueblo paraguayo, Pax Christi que informó a la Subcomisión de las consecuencias nefastas del estado de sitio, la Comisión Internacional de Juristas que apoyó la misión y el informe de Daniel O'Donnel sobre "La independencia del Poder Judicial" en referencia a la ausencia, precisamente, de independencia de la Justicia paraguaya. Esto confirma la idea de que "las instituciones internacionales, creadas por los estados para servir el interés común, provocan el anclaje y potencian a los actores no gubernamentales, dándoles los recursos, las oportunidades y la motivación gracias a las cuales pueden organizarse y movilizar a escala transnacional" (Tarrow,2006) ${ }^{22}$.

Debemos recordar que miembros de la SIJADEP, como Alejandro Artucio, son miembros a su vez, de la Comisión Internacional de Juristas que tan importante fue para documentar y denunciar el caso paraguayo así como organismos cristianos como el Consejo Mundial de Iglesias. El trabajo horizontal de estos organismos no gubernamentales de la mano con el SIJAU fue clave en la denuncia del caso paraguayo. Apoyándose en los paradigmas de la lucha sostenida por el SIJAU, sostiene Louis Joinet: "el levantamiento del estado de sitio y la amnistía no son sino medios -y no un fin en si- para llegar al verdadero objetivo que es el motivo mismo de este Coloquio: el retorno de la democracia" (SIJAU,1985). Para Joinet, es evidente que la resolución apunta a la liberación de los presos políticos y al retorno de los exiliados. Que estos dos objetivos no sean un fin en sí mismos sino los elementos que permitan crear las condiciones de una transición política reafirman la lucha defendida por el SIJAU y que reproducirá el SIJADEP, con una visión que pone en el horizonte cercano la transición política hacia un régimen en el que "la voluntad del pueblo es la base de la autoridad del poder público"23. La democracia entendida como garante último del respeto de los Derechos Humanos que constituyen el lenguaje teórico que vértebra la lucha del SIJADEP. En este sentido, el Magistrado Salvatore Senese, cerraba el coloquio que marcó el inicio del trabajo trasnacional

\footnotetext{
22 Traducción de la autora.

${ }^{23}$ Art. 21.3 de la Declaración Universal de los Derechos Humanos
} 


\section{Magdalena Schelotto Altez}

coordinado contra el régimen stronista en el Paraguay, señalando que no puede aplicarse una amnistía a los crímenes contra la humanidad cometidos por el terrorismo de Estado, pero que esos crímenes nacen de una estructura, de una doctrina, de una institución que debe ser desmantelada, evocando directamente el rol del ejército en una democracia futura. Su razonamiento no hace más que apuntalar y profundizar la posición ya marcada por Joinet y que resume la necesidad de la entrada urgente del caso paraguayo en el debate de la comunidad internacional para desterrarlo del olvido al que tantos hicieron referencia.

El tratamiento del caso paraguayo en este coloquio marcó un punto de inflexión en este sentido y su labor coordinada con otros organismos internacionales no solo romperá el silencio sobre el caso paraguayo, sino que llevará adelante ese "combate ofensivo" que defiende la amnistía como un medio, más que como un fin en si misma, tal como el SIJAU la defendió para Uruguay.

\section{El coloquio de Montevideo: Nacimiento del SIJADEP y el desafío de la comunidad internacional}

El SIJAU hará suyo el grito de los juristas paraguayos para que la comunidad internacional dejase de dar la espalda a la dictadura de Stroessner. Tanto es así que siguiendo su política de acercamiento, del 5 al 7 de diciembre de 1985 tuvo lugar el quinto coloquio del SIJAU: "Paraguay: un desafío para la responsabilidad internacional". El lugar donde se celebró, Montevideo, tenía una carga simbólica especial. Por un lado, el SIJAU que se fue acercando a Uruguay en coloquios sucesivos en San Pablo en 1983 y en Buenos Aires en 1984, esta vez ya pisaba suelo uruguayo, en un contexto donde las premisas de su lucha se cumplían gracias al retorno democrático y a la ley de amnistía. A su vez, la celebración del coloquio en la Universidad de la República supuso un momento de gran emoción en el que los uruguayos "de dentro" y los exiliados que ya podían retornar libremente, mostraron su emoción y su agradecimiento, pero también, asumían la responsabilidad de abrazar al Paraguay con la creación del SIJADEP. Según Wilder Tayler, el coloquio tuvo una muy buena asistencia en gran parte porque el convocante era respetado en Uruguay. Asistieron paraguayos de toda la oposición y prácticamente todo el espectro político uruguayo, incluyendo figuras del nuevo gobierno cuyo presidente era Julio María Sanguinetti del Partido Colorado (derecha tradicional).

La apertura del coloquio vino acompañada de un llamamiento que invitaba a juristas a firmar, convocados por el SIJADEP para:

\footnotetext{
"expresar una solidaridad activa y concreta con el pueblo paraguayo, en particular empeñando esfuerzos en la consecución de los siguientes objetivos:
}

- El levantamiento inmediato del estado de sitio 


\section{Transición y solidaridad internacional. La creación del Secretariado Internacional de Juristas para la Amnistía y la Democracia en Paraguay (SIJADEP)}

- La liberación de todos los presos políticos y una Amnistía que beneficie a todas las personas condenadas, procesadas, sancionadas y/o requeridas por motivos de represión política;

- La derogación de toda legislación represiva en materia de política, en especial las leyes 294/55 y 209/70;

- El pleno ejercicio de la soberanía popular (...)

- La afirmación de una democracia pluralista que ponga fin a toda restricción de los derechos humanos y las libertades fundamentales (...)

- La adhesión y/o ratificación de los instrumentos internacionales de protección de los derechos humanos (...)" 28 de abril de $1986^{24}$ (SIJAU, 1986)

Las intervenciones estuvieron marcadas por el contexto brasileño, argentino y uruguayo. El diálogo estuvo dominado, como ya adelantamos, por el cierre de la acción del SIJAU por Uruguay, en un clima de emoción y de agradecimiento además del compromiso con la causa paraguaya y en particular, la articulación entre acción nacional y acción internacional. Hubo participantes y observadores de Argentina, Bélgica, Bolivia, Brasil, Chile, Costa Rica, España, Estados Unidos, Francia, Gran Bretaña, Italia, Holanda, Paraguay, Perú, Suecia, Suiza, Uruguay y Venezuela (SIJAU,1986).

El coloquio estuvo presidido por: Alberto Pérez Perez, decano de la Facultad de Derecho y Ciencias Sociales de la Universidad de la República, Uruguay, Adolfo Pérez Esquivel, premio Nobel de la paz, coordinador para América Latina del SERPAJ, Servicio Paz y Justicia, Elsa Martín de Aramburu, presidenta del Colegio de Abogados del Uruguay, Alejandro Artucio, abogado, miembro del comité de dirección del SIJAU y representante de la Comisión Internacional de Juristas, Leo Matarasso, jurista francés, presidente de la Liga Internacional por los Derechos y la Liberación de los Pueblos, Amar Bentoumi, jurista argelino, secretario general de la Asociación Internacional de Juristas Demócratas, Lord Averbury, presidente del Grupo Parlamentario de Derechos Humanos en Gran Bretaña, Belisario dos Santos Jr, abogado brasileño, presidente de A.A.L.A., miembro del comité directivo del SIJAU, Justo José Prieto, abogado y profesor paraguayo, presidente de A.A.L.A. Paraguay, Jerónimo Irala Burgos, abogado y profesor paraguayo, presidente de la Comisión de DD.HH. del Paraguay, miembro del comité directivo del SIJAU y Jean-Louis Weil, jurista francés, miembro del la secretaría ejecutiva y del comité directivo del SIJAU. Antes de que se produzca ese llamamiento oficial de juristas lanzado en abril de 1986, el SIJAU ya había logrado reunir a un grupo nutrido de juristas paraguayos de diversos horizontes, personas de diferentes organismos y organizaciones no gubernamentales. En palabras del Nobel de la paz, Alfredo Pérez Esquivel: "Pero el

${ }^{24}$ Si bien el llamado fue hecho en 1985 durante la celebración del coloquio, su lanzamiento formal tuvo lugar en abril de 1986. 


\section{Magdalena Schelotto Altez}

SIJAU cumplió con su misión en Uruguay y asume la responsabilidad histórica de ponerla al servicio del pueblo paraguayo. Creo que esto es lo más valioso, lo más importante. Ya hay un camino recorrido, un trabajo hecho" (SIJAU, 1986). La metodología que se plantean para el Paraguay sigue la misma línea de acción: reclamar de forma argumentada y basándose en las leyes, asesorar jurídicamente a las víctimas, reclamar un control internacional eficaz, informar a la prensa, impulsar campañas.

En lo que concierne al contexto paraguayo, estuvo muy presente la declaración del denominado "Acuerdo Nacional" suscrito en febrero de 1979 por los siguientes partidos paraguayos: Democracia Cristiana, Liberal Radical Auténtico, Revolucionario Febrerista y Movimiento Popular Colorado. Salvo el Febrerista, ninguno de estos partidos es reconocido por el gobierno ni puede participar en elecciones nacionales o municipales ${ }^{25}$. En dicho acuerdo se establecieron 14 puntos que convocaban al pueblo paraguayo. Algunas de sus demandas habían estado muy presentes en el coloquio de Buenos Aires como la referente al levantamiento del estado de sitio. Otros puntos también hacían referencia al funcionamiento del régimen, tenían que ver con la derogación de las 209, 294 y 323 aplicadas por el régimen stronista. Se pedía también la anulación del criterio de idoneidad y de necesidad de afiliación al partido oficialista parta poder ingresar a la administración pública, a la magistratura o a magisterio. Se solicitaba la supresión de la elección indefinida y la vigencia del principio republicano de la alternación en el poder, y el rechazo de cualquier proceso tendiente a legitimar interna e internacionalmente la autocracia. A estos pedidos se sumaba la demanda de liberación de los presos políticos y sociales, la defensa y promoción de los DD.HH., tener un Poder Judicial independiente, la creación de una nueva ley electoral que impidiera el fraude y que los estatutos de los partidos políticos fuesen redactados con la participación de las organizaciones políticas. Por último, algunos puntos insistían en favorecer el ejercicio de libertades mediante la supresión del monopolio de los medios de comunicación y la plena libertad de expresión así como la defensa de la soberanía nacional.

El 14 de abril de 1984 los mismos partidos ampliaron esta declaración estableciendo además objetivos sociales, económicos, de política internacional y relativos a las Fuerzas Armadas.

Varias de estas demandas aparecerán también en el coloquio de Montevideo.

En este sentido, la primera parte del coloquio retomó la situación del orden institucional paraguayo maniatado por la vigencia del estado de sitio y la violación sistemática de los derechos civiles y políticos a pesar de una aparente apertura democrática. De hecho, en 1962 se reconoce al Partido Liberal y se autoriza su participación en las elecciones, posteriormente en 1966 se reconoce al Partido Febrerista para las elecciones comunales y finalmente en 1967 al Partido Liberal

${ }^{25}$ Benjamín Ariditi habla de "pluripartidismo limitado" ya que hay un partido dominante, partidos reconocidos, partidos tolerados pero no reconocidos y partidos proscritos (ARIDITI, 1992). 


\section{Transición y solidaridad internacional. La creación del Secretariado Internacional de Juristas para la Amnistía y la Democracia en Paraguay (SIJADEP)}

Radical para la Asamblea Nacional Constituyente. Según el abogado paraguayo, Jerónimo Irala Burgos ${ }^{26}(\operatorname{SIJAU}, 1986)$, se trata de una "mentada apertura democrática" "falaz y engañosa" y que en la práctica el funcionamiento sigue siendo "totalitario" y el partido del gobierno se identifica no solo con el gobierno sino con el propio estado, que recuerda el concepto ya mencionado de estado "omnívoro" de Benjamín Ariditi . Esto se ve respaldado por la ley electoral 886/81, que establece que dos tercios de las bancas parlamentarias sean atribuidas al que obtiene la mayoría relativa, mientras que solo el tercio restante de bancas son repartidas de forma proporcional entre los demás partidos. Además, según la mencionada ley, la propaganda política y electoral no debe atentar contra la dignidad humana ni ofender la moral pública, habilitando a la policía a prohibir toda propaganda que no cumpla dichas disposiciones. También queda prohibido cualquier lazo entre partidos paraguayos y extranjeros.

Durante el coloquio se puso de relieve cómo esta forma de sistema sistema autoritario venía además legitimado por lo que en Paraguay se conoce como "Mbareté", del guaraní, "prepotencia del poder", un código de normas no escritas que establece una estructura de rango e influencia dentro de una jerarquía de poder. Cuando este código del mbareté choca con el sistema legal, es este último el que tiene que ceder. Para William L. Wilfler ${ }^{27}$ (SIJAU, 1986) esto provoca que la ley no sea aplicada equitativamente, ya que su aplicación tiene "efectos corruptores amplios". Salvatore Senese retoma la expresión de Daniel O’Donnell: "la justicia por teléfono", señalando que "la mafia comienza allí donde se debe reclamar como un favor que obliga y ata, lo que nos corresponde por derecho" (SIJAU, 1986). De esta forma, Senese explica cómo el orden legal es remplazado por la ley del mbareté que asimila a la mafia: "esta mutación del orden jurídico paraguayo explica el agotamiento de toda vida política que fue relatado en el transcurso del coloquio" (SIJAU, 1986).

De alguna manera, las demandas que ya aparecían de forma menos estructurada en el coloquio de Buenos Aires hacen cierto eco del Acuerdo Nacional ampliado en 1984, es decir, los expertos incluyen un análisis preciso sobre la situación de los derechos económicos, sociales y culturales, entendidos como elementos esenciales para que la sociedad paraguaya pueda caminar hacia una transición política. Ocupan un lugar especial la situación del campesinado, de las poblaciones rurales y de las poblaciones indígenas por las características del país que ya hemos detallado.

Otro aspecto significativo de la situación paraguaya es el exilio de aproximadamente un tercio de la población, según los datos expuestos por Waldino Ramón Lovera ${ }^{28}$

\footnotetext{
26 Profesor de Derechos en la Universidad Católica de Asunción y en la Universidad Nacional, vicepresidente de la Comisión Paraguaya para la defensa de los DD.HH., miembro del comité directivo del SIJAU y del SIJADEP.

27 Director del Departamento de Derechos Humanos del Consejo Nacional de Iglesias de Estados Unidos.

${ }^{28}$ Waldino Ramón Lovera estuvo exiliado durante 20 años, regresó a Paraguay en 1983, era abogado y presidente del Movimiento Popular Colorado (MOPOCO).
} 


\section{Magdalena Schelotto Altez}

en el coloquio, se calculaba la cifra de un millón de personas, de las cuales, según el censo poblacional argentino de 1980, 260.000 vivían en el vecino país, aunque se estimaba que esa cifra debía subir hasta el $65 \%$ del total de exiliados. Desde el punto de vista político, Lovera denunciaba un "éxodo forzoso, programado y sistematizado" (SIJAU,1986). Los reclamos sostienen que no es solo el exilio, sino la violación de la libertad de circulación de los ciudadanos contenida en el art.56 de la Constitución paraguaya, muchos convertidos en indocumentados y algunos con la prohibición expresa de retornar como era el caso de Augusto Roa Bastos, Luis Alfonso Resck y Domingo Laíno. Los demás, si bien podían retornar, tenían el impedimento de regresar al país bajo la amenaza de enviar al exiliado en prisión apoyándose en la vigencia permanente del estado de sitio y en las leyes de seguridad nacional 294 y 209. En la resolución de la IX Asamblea de la OEA de 1979 se exhortaba al gobierno paraguayo a que implementara una amnistía amplia y generosa que beneficiara a los exiliados. En este sentido y retomando el concepto de amnistía, el SIJADEP reafirmó la necesidad de incluir garantías para los exiliados que retornaran. Entre las medidas debía incluirse, según Louis Joinet (SIJAU, 1986), el goce del pleno derecho de la libre circulación, sin estipular plazos. Esto y medidas como las de acogida y de reinserción profesional garantizarían una mayor eficacia de la ley.

Para el caso de los llamados delitos de opinión, Joinet afirma que era una figura no reconocida por el derecho internacional, tratándose así de una detención arbitraria y por lo tanto a su juicio, esos presos debían ser liberados sin esperar la ley de amnistía. En el caso de las violaciones de derechos humanos, Joinet y el SIJADEP defiendían que cuando existía tortura, desaparición involuntaria o forzada o ejecución extrajudicial como "práctica administrativa", debían ser calificados como crímenes contra la humanidad, y por lo tanto debían ser imprescriptibles. El magistrado francés hablaba de la práctica administrativa entendida como "una acumulación de faltas de naturaleza idéntica o análoga, suficientemente numerosas, ligadas entre si (que no pueden ser reducidas a incidentes aislados o excepcionales), al punto de formar un conjunto o sistema" (SIJAU,1986) y que eran toleradas por las autoridades superiores del país. Durante su intervención, Joinet reconoció que esto suponía un debate difícil en Naciones Unidas, en parte porque ningún derecho interno reconocía en aquel momento, la calificación de crimen contra la humanidad para actos cometidos con posterioridad a la segunda guerra mundial y sin relación con ella. En este sentido, como sabemos y evidencia la formulación teórica de las demandas de amnistía "ofensiva" del SIJAU y posteriormente del SIJADEP para Paraguay, América Latina sentó el precedente para que este aspecto del derecho evolucionara, no en vano, el propio Louis Joinet redactó el 1988 la primera 


\section{Transición y solidaridad internacional. La creación del Secretariado Internacional de Juristas para la Amnistía y la Democracia en Paraguay (SIJADEP)}

declaración de la ONU contra la desaparición forzada ${ }^{29}$ y será el redactor de la Convención Internacional sobre el tema ${ }^{30}$.

En el debate existe la conciencia de que los aires de democracia en el Cono Sur comienzan a ser absorbidos por los paraguayos, esencialmente para "insuflar fe a los demócratas del Paraguay, reviviendo la esperanza del pueblo" como sostenía José Félix Fernández Estigarribia (SIJAU, 1986) para que el pueblo paraguayo pudiera sacudirse de la dictadura que lo asfixiaba. Pero también como sentimiento de que Paraguay debía formar parte de la "Patria Grande Latinoamericana" de pueblos libres. En este sentido, el abogado uruguayo Helios Sarthou, propugnaba por hacer una operación "desbalcanizadora de América Latina" (SIJAU,1986). Es decir, terminar con la división de los países latinoamericanos. Sarthou habla de un panamericanismo que lograrían los pueblos latinoamericanos "y los hombres de aquí, del SIJAU, de otras organizaciones, que están trabajando, porque por encima de fronteras hemos sentido, en momentos difíciles en nuestro país, que se estaban ocupando de este pequeño paisito". Sarthou introduce otro elemento interesante para el debate de la transición, el imperativo de unidad: "les decimos a los amigos paraguayos: es muy importante ser uno frente a la dictadura. Las divisiones, las diferencias, son para mañana" (SIJAU,1986). Así como en el primer coloquio el mensaje de sacar a Paraguay del olvido se repetía, esta idea de trabajar unidos contra la dictadura será un elemento presente en el coloquio de Montevideo. En su informe general, Salvatore Senese señala que el compromiso jurídico adquiere un valor político que "reclama la unidad de todas las distintas fuerzas" por ello debe "primar la unidad porque este estatuto constituye el punto de partida para que las diversidades políticas puedan manifestarse". En esta línea, el político uruguayo Alberto Zumarán, saludaba la presencia plural de políticos paraguayos. Retomando el caso uruguayo, indicaba que para él, la unidad de las luchas democráticas, partidos políticos y organizaciones sociales fue el "gran motor. No hay dictadura, por más años que tenga, por más enraizada que esté en la sociedad, que resista a un frente opositor unido. Y esto me parece que es el gran paso" (SIJAU,1986). En este sentido, Tayler insistió en la presencia de una oposición paraguaya muy fragmentada y que fue ahí donde el papel del SIJADEP fue clave ya que buscaba hacer de amalgama a través del elemento común del lenguaje de los Derechos Humanos, de tal forma que les permitiera hacer acuerdos.

Por último, un aspecto importante de la solidaridad internacional destaca en el caso paraguayo y es la presencia ecuménica. Si ya habíamos notado la presencia de responsables de organismos cristianos, la participación del responsable de DD.HH del Consejo Mundial de Iglesias sección América Latina bajo la presencia de Charles Harper permite señalar la participación y el papel de las iglesias cristianas en la

${ }^{29}$ Conjunto de Principios para la protección de todas las personas sometidas a cualquier forma de detención o prisión. Adoptado por la Asamblea General en su resolución 43/173, de 9 de diciembre de 1988.

${ }^{30}$ https://www.ohchr.org/SP/ProfessionalInterest/Pages/ConventionCED.aspx 
lucha por la defensa y promoción de los derechos humanos en Paraguay. En particular, con detenidos, presos y torturados pero también con grupos vulnerables como el campesinado sin tierra y los colectivos indígenas. Harper destaca el rol del Comité de Iglesias para Ayudas de Emergencia que existe en el país guaraní. Además, el Comité Mundial de Iglesias, era uno de los organismos consultivos ante el Consejo Económico y social de la ONU. Esto permitió, que en febrero de 1985, el CMI presentara un informe sobre la situación del país, con el apoyo de las iglesias cristianas paraguayas durante el 41avo período de sesiones de la Comisión de DD.HH de Naciones Unidas en el que hablan de "cadena sistemática de opresión desde hace más de 30 años" (SIJAU,1986) y piden el cese inmediato del estado de sitio y la amnistía. Esta concepción cristiana está evidentemente impregnada del discurso de la Teología de la liberación ${ }^{31}$ ya que el CMI defiende asistir y apoyar a las víctimas, ir más allá de la asistencia cuando son violados los derechos humanos, tratar de restablecer la integridad y la dignidad de la política. Con un mensaje sin vacilaciones en este sentido, Harper termina su discurso afirmando:

\begin{abstract}
"también el estado ha tratado de domesticar la teología y distorsionarla para justificar políticas de represión y de doctrina de la seguridad nacional. Nosotros rechazamos esto como herejía y abuso. La verdadera teología y el rol verdadero de la ley, es la de servir al pueblo y a sus intereses. En el centro del Antiguo y del Nuevo Testamento y en la esencia del Evangelio, está la libertad de toda opresión y el mensaje de esperanza. Esto sirve como principio orientador para la comunidad cristiana y ecuménica en la lucha por la justicia en el Paraguay". (SIJAU,1986)
\end{abstract}

En concomitancia con lo sostenido por el representante del CMI, la intervención de Tran Van Minh, jurista de origen vietnamita y docente en la Universidad Paris II señalaba que las garantías de una verdadera transición democrática en el Paraguay debían apoyarse en tres condiciones esenciales: la participación del pueblo en la transición, el respeto del Estado de derecho y la necesidad de un medio

31 En América Latina, el Concilio Vaticano II (1962-1965), las Conferencias de Obispos Latinoamericanos de Medellín (1968) y Puebla (1979) cambian la visión y práctica del catolicismo de forma radical, en estos eventos se concluyó una opción clara en defensa de los pobres y de los más desfavorecidos. No podemos olvidar que una parte de la iglesia también apoyó las dictaduras pero no nos interesa para este caso particular y por ello no lo desarrollamos. Estos fundamentos fueron la base para la protesta contra las violaciones cometidas por los gobiernos de facto. De hecho, a modo de ejemplo, el periódico español El Pais, se hacía eco de las manifestaciones en contra del gobierno $\begin{array}{lllll}\text { de Stroessner } & \text { en } & \text { agosto } & \text { de } & 1988\end{array}$ https://elpais.com/diario/1988/08/08/internacional/586994416 850215.html. Para más información: Carter, Miguel: El papel de la Iglesia en la caída de Stroessner, Asunción, RP Ediciones, 1991, p. 83. En el siguiente artículo se ve de forma interesante el vínculo con los estudios sociales así como el rol de la iglesia ligada a la Teología de la liberación en las Ligas Agrarias: Lorena Soler, " "De pronto la Iglesia nos obligó a ser sociólogos". Socialización política y stronismo. Los estudiantes de sociología de la Universidad Católica de Asunción (1971-1976) », Nuevo Mundo Mundos Nuevos [En línea], Cuestiones del tiempo presente, Puesto en línea el 31 marzo 2014. URL: http://journals.openedition.org/nuevomundo/66560 ;

DOI :

https://doi.org/10.4000/nuevomundo.66560 


\section{Transición y solidaridad internacional. La creación del Secretariado Internacional de Juristas para la Amnistía y la Democracia en Paraguay (SIJADEP)}

internacional favorable que podía expresarse "en la puesta en marcha de esos principios de solidaridad democrática, en la creación de una especie de "espacio de libertad" que implica la cooperación y la solidaridad entre los países que ingresan en la transición democrática" (SIJAU,1986). En este sentido, señalaba que América Latina había aprendido que el presidencialismo tendía a la concentración de poderes y por ello, había dado lugar a la creación de "contra poderes frente al poder del Estado" (SIJAU, 1986). Es en este grupo que Tran Van Minh incluye y destaca a la iglesia como agente esencial en la defensa de los derechos y de las libertades, así como de la justicia social, "con la reciente teología de la liberación, la Iglesia latinoamericana enriqueció el mensaje evangélico con una nueva dimensión”.

\section{Conclusiones}

Si bien el período de funcionamiento del SIJADEP es bastante limitado en el tiempo, desde el coloquio de Montevideo hasta 1989, en comparación con el del SIJAU y nuestro trabajo aborda únicamente los dos eventos que marcan su creación, esto nos permite acercarnos a la dictadura más dilatada del Cono Sur, a sus características y sobre todo, conocer las bases teóricas y prácticas del SIJADEP, sus integrantes y cómo se orientan los esfuerzos para apoyar una transición democrática en Paraguay.

Hemos podido comprobar cómo el contexto temporal y geográfico fueron determinantes para que ambos coloquios fueran llevados a cabo. El lugar elegido para su realización tiene una carga simbólica doble, por un lado, los países que acogen los coloquios acaban de realizar esa transición democrática. Este punto está más presente en el caso uruguayo, ya que el SIJAU, al origen del Secretariado Internacional de Juristas por la Amnistía y la democracia en el Paraguay y con el que guarda total continuidad, había trabajado de forma incansable para que el Uruguay dejara atrás la dictadura y en las condiciones políticas que en ese momento se estaban dando. Supuso un encuentro con gente por la que y con la que habían luchado y que en esa ocasión tenía la oportunidad de acoger y agradecer la labor del SIJAU. Por otro lado, para el país que nos ocupa, la localización suponía un acercamiento geográfico pero sobre todo, el comienzo de la solidaridad latinoamericana que hasta entonces solo parecía funcionar en el caso de la coordinación represiva.

La circulación indudable, humana, de conocimientos, de experiencias y de práctica jurídica permite que el caso paraguayo llegue a las altas instancias de derechos humanos, apoyada en esa tríada formada por paraguayos, organismos no gubernamentales y organizaciones trasnacionales de derechos humanos. En el caso de los ciudadanos, parte importante de esa voz, es ocupada por los exiliados, a los que poco a poco se suman juristas que aún trabajan en Paraguay y que denuncian 


\section{Magdalena Schelotto Altez}

un falso sistema democrático. El conocimiento de los juristas locales siempre es esencial para que el SIJADEP pueda tener un conocimiento cabal de la situación y conozca el ordenamiento jurídico paraguayo para denunciar las violaciones o aprovechar sus fallas. El eslabón esencial que permite funcionar esta cadena es el lenguaje trasnacional de los Derechos Dumanos. Este lenguaje, elegido y defendido de forma vehemente por el SIJAU primero y por el SIJADEP después, ya que permite canalizar el mensaje de la militancia exiliada, dejando de lado el componente político, en el sentido partidario, y además, garantiza la aceptación en los organismos donde se espera que tengan eco sus acciones para que su lucha tenga consecuencias para el gobierno opresor de Stroessner.

El lenguaje de los Derechos Humanos, es enarbolado por el SIJADEP, no como un elemento pasivo sino, como un agente de cambio. El análisis hecho por sus portavoces, tales como Louis Joinet o Jean-Louis Weil, señalan esa lucha por una amnistía "ofensiva", que ya en su estado defensivo no siempre existe en el derecho internacional. En el caso paraguayo, la amnistía va especialmente volcada al exilio, para que puedan retornar libremente. Su discurso les aporta una capacidad de ver más allá de la mera consecución de los objetivos que prodigan. En este sentido, es sintomático que criticaran el delito de opinión, desacreditando su validez, pero especialmente, que su discurso adelantara una concepción de la violación de los derechos humanos que hasta entonces, solo se había aplicado tras el Holocausto pero que en América Latina recobrará un nuevo sentido y sobre todo, pondrá en evidencia la necesidad de la protección de esos derechos. El trabajo llevado a cabo por Louis Joinet en cuanto a la desaparición forzada o la tortura beben de esta larga experiencia latinoamericana.

\section{Bibliografía}

Ariditi, Benjamin (1992) Adiós a Stroessner. La reconstrucción de la política en el Paraguay. Centro de Documentos y Estudios. Asunción, Paraguay.

Céspedes, L. Demanda social, Política y Autoritarismo. Senderos paralelos frente a una dictadura prolongada, Revista Paraguaya de Sociología, Año 25, № 73 (Sep.Dic., 1989), pp.237-238.

Fondo SIJAU-Weil Uruguay. La Contemporaine. Nanterre, Francia.

Lesgart, Cecilia (2002). Usos de la transición a la democracia. Ensayo, ciencia y política en la década del ochenta. Estudios Sociales, Año XII, № 22-23, Santa Fé, Argentina, Universidad Nacional de Litoral, pp. 163-185. 


\section{Transición y solidaridad internacional. La creación del Secretariado Internacional de Juristas para la Amnistía y la Democracia en Paraguay (SIJADEP)}

López, Magdalena (2010). "La democracia en Paraguay. Un breve repaso sobre los partidos políticos tradicionales, el sistema electoral y el triunfo de Fernando Lugo Méndez". Revista Enfoques, volumen VIII, №13, pp. 89-106.

O’Donnell, G. Schmitter, Ph., Whitehead, L., Transiciones desde un gobierno autoritario. América Latina, Buenos Aires, Paidós, 1988.

Rousso de Pagno, Elena (-). La Transición a la Democracia en América Latina". El caso paraguayo (1989-1993). Facultad de Humanidades, Universidad Nacional del Nordeste.

Schelotto Altez, Magdalena (2014). Aplicación de una metodología de análisis del discurso: la amnistía en el Uruguay post-dictatorial (tesis de doctorado inédita). Universidad Carlos III, Madrid, España.

SIJAU (1985). Uruguay y Paraguay: La transición del estado de excepción a la democracia. SIJAU, Ediciones de la Banda Oriental, temas del siglo XX, Montevideo.

SIJAU (1986). Paraguay: un desafío de la responsabilidad internacional. Ediciones de la Banda Oriental/SIJADEP, temas del siglo XX, Montevideo.

SIJAU, Informe del coloquio: "La Amnistía en el Uruguay: efectos jurídicos, fundamentos, alcance y aplicación", San Pablo, Brasil, junio de 1983.

Tarrow, Sidney (2000), La constestation transnationale. Cultures \& conflits (En ligne), 38-39 été-automne 2000 pp. 187-223, mis en ligne le 20 mars 2006. URL : http://journals.openedition.org/conflits/276 ;

DOI : https://doi.org/10.4000/conflits.276

Tayler, Wilder (2019). Entrevista con la autora el 21 de noviembre de 2019.

WOLA (1988). Decline of the dictator: Paraguay at a crossroads.

Recibido: $10 / 01 / 2020$

Evaluado: $15 / 02 / 2020$

Versión Final: 30/03/2020 